\title{
Treatment of caustic esophageal injury: The source of knowledge is experience
}

\author{
Victor A. Ferraris, MD, PhD \\ From the Division of Cardiovascular and Thoracic Surgery, Department of Surgery, Chandler School of Medicine, \\ University of Kentucky, Lexington, Ky. \\ Disclosures: Author has nothing to disclose with regard to commercial support. \\ Received for publication Aug 3, 2016; accepted for publication Aug 6, 2016; available ahead of print Sept 1, 2016. \\ Address for reprints: Victor A. Ferraris, MD, PhD, University of Kentucky College of Medicine, Division of \\ Cardiovascular and Thoracic Surgery, 740 S Limestone Ave, A-301, Lexington, KY 40536-020 (E-mail: \\ ferraris@uky.edu). \\ J Thorac Cardiovasc Surg 2016;152:1386-7 \\ $0022-5223 / \$ 36.00$ \\ Copyright $(2) 2016$ by The American Association for Thoracic Surgery \\ http://dx.doi.org/10.1016/j.jtcvs.2016.08.005
}

Caustic ingestions may cause widespread injury to the aerodigestive tract, including the lips, oral cavity, pharynx, upper airway, esophagus, and stomach. Multiple caustic substances can cause esophageal injury (Table 1). The effect of ingestion of these toxic substances on the esophagus accounts for most of the serious injuries and adverse long-term sequelae. The signs and symptoms of ingestion of caustic substances do not adequately predict the presence or severity of esophageal injury. ${ }^{1,2}$ The patient age at occurrence of these ingestions shows a bimodal pattern. The first peak occurs in young children, with most of these ingestions being accidental. The other peak age for caustic ingestion occurs in young adults, mostly related to suicide attempts. In children, caustic ingestions translate into esophageal burns in fewer than $50 \%$ of patients, whereas adults usually have a much higher rate of esophageal injury because of the ingestion of larger amounts of concentrated toxic substances and prolonged exposure time. ${ }^{3}$ Caustic ingestions in elderly patients are particularly bad, with mortality and morbidity rates 3 to 4 times greater than those in younger patients. ${ }^{4}$ There is some indication that accidental caustic ingestions in children are decreasing in developed countries, but caustic ingestion injuries remain a prevalent problem in developing countries. ${ }^{5}$

Clinical management of caustic ingestions includes early endoscopy, chest and abdomen computed tomography, possibly early bougienage with or without early stent placement, and, in extreme situations, esophagogastrectomy with delayed reconstruction. Early computed tomographic findings may facilitate the decision to perform emergency esophagectomy for endoscopic high-grade corrosive esophageal injury. ${ }^{6}$ Under certain circumstances, conservative management of caustic injuries is feasible, avoids the need for esophagogastric resection, and may provide better long-term nutritional benefit and improved quality of life. Nonoperative management often results in esophageal stricture, necessitating long-term interventions. ${ }^{8,9}$ Caustic

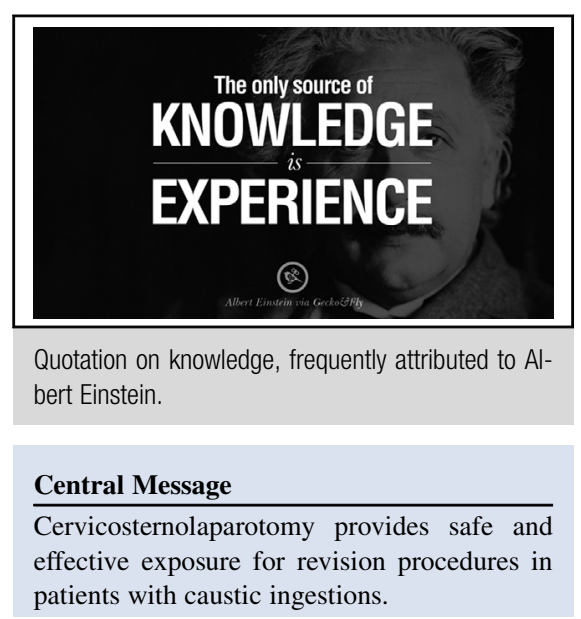

See Article page 1378 .

ingestions that cause severe pharyngeal and esophageal injury requiring colopharyngoplasty are among the most debilitating injuries with the poorest long-term results. ${ }^{10}$

In the most severe caustic ingestion injuries, esophageal resection and reconstruction with colon is the most reliable procedure, with long-term proven benefit. ${ }^{11}$ Because of the relative rarity of esophageal caustic injuries requiring esophagectomy, there are very few studies that address the complications of surgical treatment of corrosive esophageal injuries. In this issue of the Journal, Voron and coauthors ${ }^{12}$ present a truly remarkable series of 100 patients who required revision procedures to the esophagus injured by caustic ingestion, with primary emphasis on the use of cervicosternolaparotomy for exposure to perform these complicated operations. These authors have a broad experience in dealing with caustic ingestion injuries and have published widely on this subject. ${ }^{2,6,10,13}$ It helps to understand that this impressive experience comes from the Hôpital Saint-Louis in Paris. This hospital was founded by King Henry IV in 1607 to decongest the Hôtel-Dieu de Paris during the plague. The King named it Saint-Louis in memory of King Louis IX, who died of the plague that devastated Tunis in 1270. This hospital is part of the Assistance Publique-Hôpitaux de Paris, which is the public hospital system of the city of Paris and its suburbs. It is the largest hospital system in Europe and employs more than 90,000 people (including 15,800 physicians) in 44 hospitals and receives more than 5.8 million annual patient visits. As a public hospital that is part of the Assistance Publique-Hôpitaux de Paris, the Hôpital Saint-Louis is 
TABLE 1. Commonly ingested caustic and corrosive agents ${ }^{3}$

\begin{tabular}{lc}
\hline \multicolumn{1}{c}{ Type } & Example \\
\hline Alkali & Sodium hydroxide, potassium hydroxide, (oven cleaners, liquid agents, liquid drain cleaners, disk batteries), \\
& calcium and lithium hydroxide (hair relaxers), ammonia (household cleaners), dishwater detergents \\
Acid & Sulfuric acid, hydrochloric acid, nitric acid (toilet bowl cleaners, swimming pool cleaners, rust removers) \\
Bleaches and other caustics & Hypochlorous acid (bleach—generally neutral pH commercially), peroxide (mildew remover) \\
\hline
\end{tabular}

situated in the northeast of Paris and can serve as entry point for all types of trauma. Surgeons there treated the recent terrorist attack at the Bataclan concert hall in Paris (http:// www.dailymail.co.uk/news/article-3320843/Stretchedbreaking-point-surgeons-pictured-crammed-Paris-hospitalfought-save-lives-terror-attack-victims.html). Paris is a city of more than 15 million people, and the diversity of the patients that seek care at the Hôpital Saint-Louis undoubtedly accounts for the broad experience with caustic ingestions and the unusually large number of revision procedures described in the article by Voron and coauthors. ${ }^{12}$

One thing that comes across in reading the article by Voron and coauthors ${ }^{12}$ is the frequent need for revision procedures in patients with caustic injury. The authors serve as a referral source for these complicated procedures. The article does not provide an estimate of the total population affected by caustic ingestion; however, the reader cannot help but be amazed at how many total patients must have had a caustic ingestion to provide a population of 100 patients in need of some form of revision. Voron and coauthors $^{12}$ clearly have the benefit of a large referral population and vast medical infrastructure in the Assistance Publique-Hôpitaux de Paris. I wonder about the factors that translate into this robust experience in rescue procedures for caustic ingestions. Whatever contributes to this experience, it is clear that the abundant practice dealing with this uncommon problem has taught these surgeons how to obtain very good outcomes. This seems to be an argument in favor of localization of resources to a single center. Voron and coauthors ${ }^{12}$ have translated their experience into knowledge that can help other surgeons deal with this difficult problem. Albert Einstein is frequently given credit for the quote, "The only source of knowledge is experience." This seems to apply to the work of Voron and coauthors. ${ }^{12}$

\section{References}

1. Gaudreault P, Parent M, McGuigan MA, Chicoine L, Lovejoy FH Jr. Predictability of esophageal injury from signs and symptoms: a study of caustic ingestion in 378 children. Pediatrics. 1983;71:767-70.

2. Sarfati E, Gossot D, Assens P, Celerier M. Management of caustic ingestion in adults. Br J Surg. 1987;74:146-8.

3. Lupa M, Magne J, Guarisco JL, Amedee R. Update on the diagnosis and treatment of caustic ingestion. Ochsner J. 2009;9:54-9.

4. Chang JM, Liu NJ, Pai BC, Liu YH, Tsai MH, Lee CS, et al. The role of age in predicting the outcome of caustic ingestion in adults: a retrospective analysis. BMC Gastroenterol. 2011;11:72.

5. Adedeji TO, Tobih JE, Olaosun AO, Sogebi OA. Corrosive oesophageal injuries: a preventable menace. Pan Afr Med J. 2013;15:11.

6. Chirica M, Resche-Rigon M, Pariente B, Fieux F, Sabatier F, Loiseaux F, et al. Computed tomography evaluation of high-grade esophageal necrosis after corrosive ingestion to avoid unnecessary esophagectomy. Surg Endosc. 2015; 29:1452-61

7. Raynaud K, Seguy D, Rogosnitzky M, Saulnier F, Pruvot FR, Zerbib P. Conservative management of severe caustic injuries during acute phase leads to superior long-term nutritional and quality of life (QoL) outcome. Langenbecks Arch Surg. 2016;401:81-7.

8. Ferguson MK, Migliore M, Staszak VM, Little AG. Early evaluation and therapy for caustic esophageal injury. Am J Surg. 1989;157:116-20.

9. Zhou JH, Jiang YG, Wang RW, Lin YD, Gong TQ, Zhao YP, et al. Management of corrosive esophageal burns in 149 cases. J Thorac Cardiovasc Surg. 2005;130:449-55.

10. Chirica M, Brette MD, Faron M, Munoz Bongrand N, Halimi B, Laborde C, et al. Upper digestive tract reconstruction for caustic injuries. Ann Surg. 2015;261:894-901.

11. Ananthakrishnan N, Subbarao KS, Parthasarathy G, Kate V, Kalayarasan R. Long term results of esophageal bypass for corrosive strictures without esophageal resection using a modified left colon esophagocoloplasty-a report of 105 consecutive patients from a single unit over 30 years. Hepatogastroenterology. 2014;61:1033-41.

12. Voron T, Anyla M, Corte H, Roland E, Munoz-Bongrand N, Sarfati E, et al. The cervicosternolaparotomy approach for the treatment of graft dysfunction after retrosternal esophageal reconstruction for caustic injuries. J Thorac Cardiovasc Surg. 2016;152:1378-85.

13. Cattan P, Chiche P, Berney T, Halimi B, Aïdan K, Célérier M, et al. Surgical approach by cervicosternolaparotomy for the treatment of extended cervical stenoses after reconstruction for caustic injury. J Thorac Cardiovasc Surg. 2001;122:384-6. 